\section{Imaging Degraded Wood by Confocal Microscopy}

Yoon Soo KIM* and Adya Singh

New Zealand Forest Research Institute, Private Bag 3020 , Rotorua, New Zealand.

The application of confocal laser scanning microscopy (CLSM) in the studies of biological materials is rapidly expanding because of the opportunity to produce sharp, high resolution images through optical sectioning and computer assisted 3-D reconstruction. At our institute CLSM is being used in a wide range of forestry and wood science studies.

Recently we investigated the potential usefulness of CLSM in characterizing biologically degraded wood. The following are images produced from an archaeological wood which has been buried in a wet environment (rice field) for nearly 2,000 years in South Korea and is apparently degraded by bacteria. In an attempt to develop suitable techniques which can be used for routine examination of fragile degraded wood with CLSM, we have compared two different embedding methods for their suitability in preserving the integrity of cells. The embedding media are paraffin wax and LR White resin.

The illustrations (Figures 1, 2, and 3) provide a comparison of the images of degraded wood tissues embedded in paraffin wax and deparaffinized with xylene, embedded in paraffin wax but not deparaffinized, and embedded in LR White resin, respectively. Specimens fixed with glutaraldehyde and paraformaldehyde $(1: 1, w / v)$ were examined in a Leica TCS/NT CLSM using wavelengths of 488 and $568 \mathrm{~nm}$ for excitation and 530 and 590 $\mathrm{nm}$ for imaging with a $63 \mathrm{X}$ oil immersion lens. Specimens were observed directly after sectioning (15 $\mu \mathrm{m}$ thick for wax-embedded and $4 \mu \mathrm{m}$ thick for resin-embedded samples) without treatment with any fluorescent dyes, using the autofluorescence of lignin present in wood cell walls. All images are sharp with a high contrast between the degraded and undegraded parts of wood cell walls, and this has made it possible for us to make critical comments on the advantages and disadvantages of the methods used. It is apparent that in Figure 1 few cells are intact, whereas in Figure 3 all cells retain their integrity, with the heavily degraded parts of wood cell walls being also well preserved as wall residues. The quality of preservation of the integrity of wood cells in Figure 2 is intermediate between the two.

Clearly paraffin wax embedding cannot be a method of choice for confocal microscopy of degraded archaeological wood (This may also apply to other degraded woods which are fragile), although paraffin embedded biological materials have been widely examined in confocal studies, particularly in medical sciences. We therefore suggest that anyone interested in the imaging of degraded wood tissues should use resin and not paraffin wax as an embedding material. However, if it is absolutely necessary to use paraffin to save time in processing samples or if there is no access to an ultramicrotome, paraffin embedded sections should not be deparaffinized.

*Permanent address: Dept. Forest Products and Technology, Chonnam National University, Kwangju 500-757, South Korea. This work was supported in part by a grant from YSK from the Korea Research Foundation during his stay in NZFRI.

\section{$\Rightarrow$}

Figures 1 - 3. Images of waterlogged archaeological wood (oak; Quercus spp.) depending upon the different embedding methods. 1) Sample embedded with paraffin and deparaffinized with xylene. 2) Same sample embedded with paraffin but not deparaffinized. 3). Image of same sample embedded with $L R$ White. Bar $=16 \mu \mathrm{m}$.
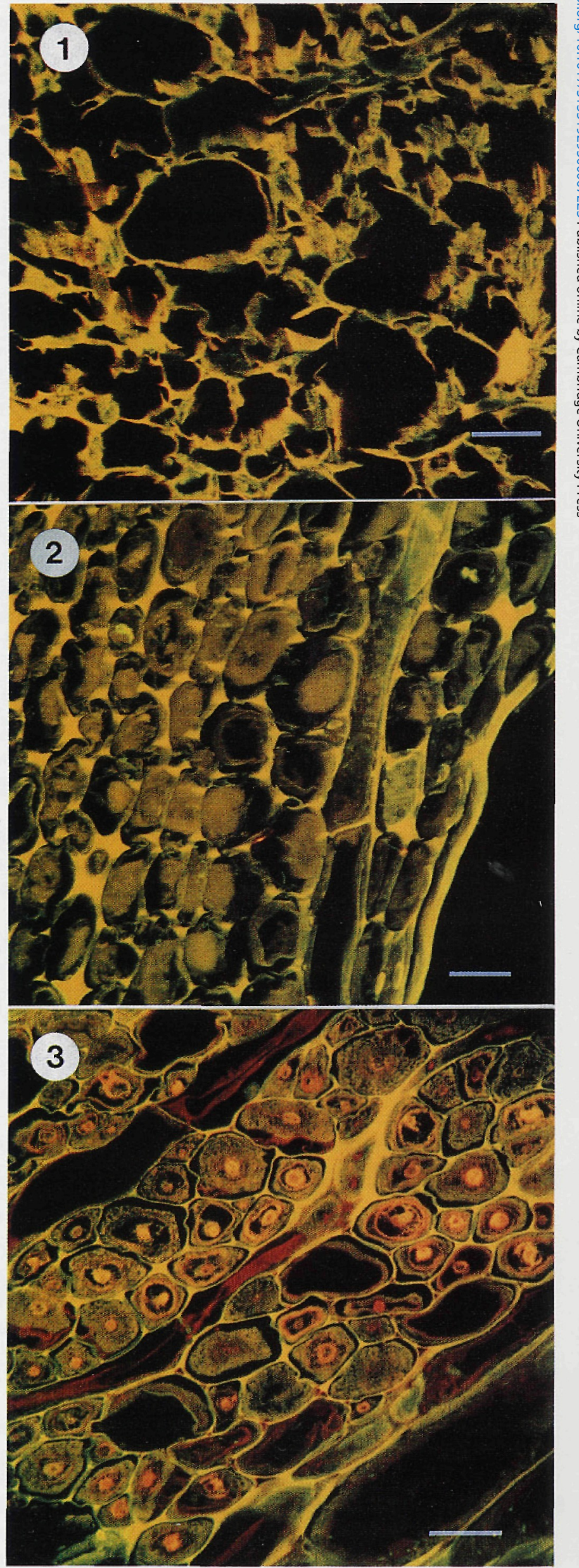

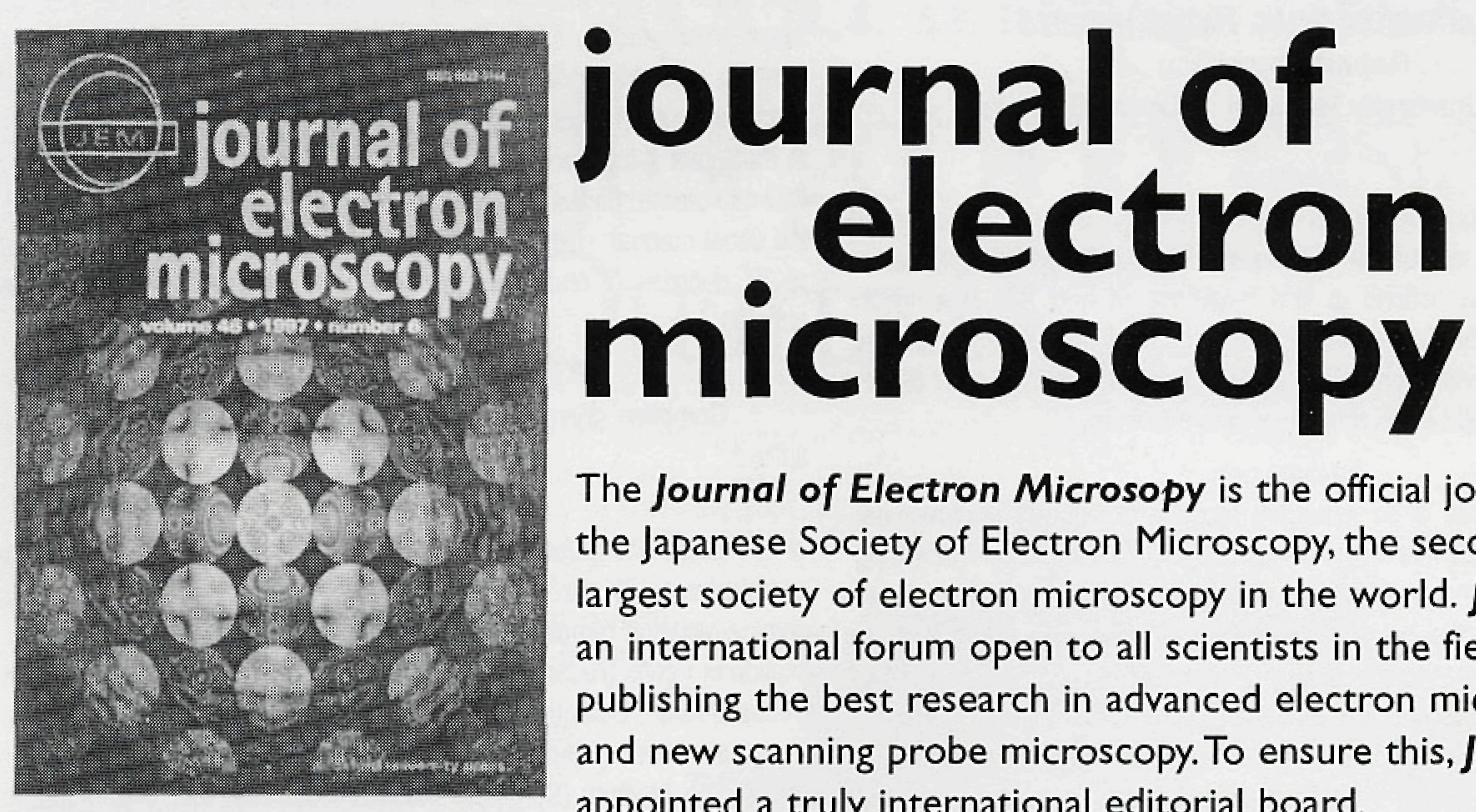

The Journal of Electron Microsopy is the official journal of the Japanese Society of Electron Microscopy, the second largest society of electron microscopy in the world. JEM is an international forum open to all scientists in the field for publishing the best research in advanced electron microscopy and new scanning probe microscopy. To ensure this, JEM has appointed a truly international editorial board.

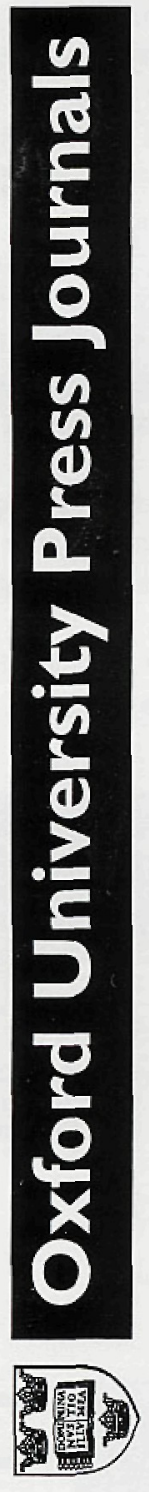

Forthcoming articles in The Journal of Electron Microscopy:

- Development of a new 3 MV ultra-high voltage electron microscope at Osaka University

- Grain boundary structure and chemical bonding state of superplastic $\mathrm{SiO}_{2}$-doped TZP

- Note. Quantitative analysis of a high-resolution electron microscopy image of $\mathrm{WO}_{3}$ block structure with a residual index

- Electron microscopic study of erythroblastic islands obtained by 'tissue-stamp culture' method

- Podocytes of the freshwater shrimp - fine structure and effect of injected trypan blue

- Letter. Occurrence of capillaries with fenestrae in the intrinsic laryngeal muscles of the guinea pig

- Letter. Neurite formation induced in neuroblastoma cells and genetically altered non-neuronal cells

Visit our website for more information for researchers, authors, subscribers, or anyone in the field. Bookmark it today!

http://www.oup.co.uk/jmicro/?ex

Send orders accompanied by the correct payment to In North America: Journals Marketing, Oxford University Press, 2001 Evans Road, Cary, NC 27513, USA.

Elsewhere: Journals Department, Oxford University Press, Great Clarendon Street, Oxford OX2 6DP, UK.

Fax or Phone

Credit card orders may be placed by phone or fax. In the Americas: Call (919) 677-0977, or (800) $852-7372$ (USA and Canada only), Fax: (919) 677-1714, E-mail: jnlorders@oup-usa.org. Elsewhere: Call $+44(0)$ 1865267907 Fax: $+44(0)$ 1865267485 , E-mail jnlorders@oup.co.uk.

\section{Please enter my 1998 subscription (6 issues) to the} Journal of Electron Microscopy

Individuals: $\$ 275 / £ 170$

$\square$ MSA/RMS/ASEM/BMS/EMAG/SCANDEM/SSOEM Members: $\$ 125 / £ 80$ (ESterling rates apply in Europe, US\$ elswhere. Contact OUP for details on society memeberships.)

$\square$ I enclose a check made payable to Oxford University Press. $\square$ I am interested in subscribing; please send me a free sample copy. $\square$ Please charge my MCard/Visa/Amex/Diners/JCB (circle one)

Name

Address

City

State/Province Zip/Postcode

Card no

Exp. Date microex

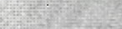

Signature: 